Methods 378 pushing and pulling test sessions were organised. Forces were measured by means of a computerised dynamometer $(200 \mathrm{~Hz}, 120 \mathrm{Kg}$ scale). 3 health operators $(\mathrm{OH})$ and 2 very trained technicians (T) moved 2 types of hospital beds carrying simulated loads of patients weighting 70, 90 and $110 \mathrm{Kg}$, on a maximum distance of $300 \mathrm{~m}$. To assess the speed limit ( $1 \mathrm{~m} /$ second) compliance, a $20 \mathrm{~m}$ pushing test was repeated multiple times by each tester. The same $20 \mathrm{~m}$ test provided individual threshold to compute initial and sustained forces. Initial force was defined as value lying above the threshold, the hysteresis curve and only for coherent data. To compare the speed suggested by the methods with the real speed performed by operators, a 2 months analysis of the patient transportation recorded missions was carried out. Then the accumulated delay-times were estimated with reference to the mean travel time measured at the suggest speed.

Results Initial forces resulted 43\% (32\%-112\%) and sustained forces 37\% (23\%-101\%) higher and statistically significant for $\mathrm{OH}$ compared to T. Increased speed saves only $25 \%(12 \%-56 \%)$ of the travel time, due to elevators waiting, doors opening etc.

Conclusion Rapidly grooving hospitals often show tortuous paths, where patient transportation on bed is allowed. ISO11228-2 assessment method contribute to solve complex measures, particularly when dealing very long distance pushing and pulling tasks. Initial forces might be calculated by measuring the threshold of the initial force of each operator on a $20 \mathrm{~m}$ test. Mean delay time shows risk excess often leading to increased speed behaviours.

\section{Ageing and Work}

\section{STAYING AT WORK WHILE AGEING: BARRIERS AND FACILITATORS FOR WORKERS OVER 55 YEARS OF AGE}

M-J Durand*, M-F Coutu. Université de Sherbrooke, Longueuil, Canada

\subsection{6/oemed-2018-ICOHabstracts.92}

Introduction While ageing workers (AWs) ( $\geq 55$ years) constitute a growing portion of the labour force, they tend to be absent for health reasons more often than other workers. However, implementing mechanisms that facilitate their staying at work implies first understanding the contributing factors and dynamics.

Methods A multimethod approach was used, combining a literature review and a series of group discussions with stakeholders in work disability. First, a rapid review of mixed studies (qualitative, quantitative, mixed) was carried out between 2006 and 2016 using main databases (e.g.: CINAHL, PsycInfo, Sociological Index). We identified 30 articles on AWs and various causes of disability, then analysed the article content using a predefined extraction grid. Four focus groups representing various stakeholders $(n=35)$ concerned by the ageing of workers in Quebec, Canada, were formed (insurers, employers, unions, health professionals). The discussions were transcribed and content analysis was performed.

Results Combined results revealed that the relationship between ageing and the likelihood of staying at work is largely influenced by the interactions between workers' personal systems and the organisation's (workplace) system. The gap between workers' representations, capacities and resources, on the one hand, and employers' expectations and requirements and the conditions they provide, on the other, significantly impacts the likelihood of AWs staying at work.

Discussion The likelihood of AWs staying at work appears closely linked to the workplace's dynamic capacity to take into account their specific health conditions and needs. This presupposes, however, recognition of AWs' added value, in a market characterised by ever-growing concern with maximising performance. The actions associated with the different systems (e.g. compensation and healthcare systems) also need to be harmonised to maximise the stay-at-work potential of this segment of the labour force.

\section{AGEING AND INTERVENTIONS}

Clas-Håkan Nygård*. University of Tampere, Finland

\subsection{6/oemed-2018-ICOHabstracts.93}

Aim of special sessions To show and discuss results from interventions among ageing workers in different occupations.

${ }^{1}$ Subas Neupane, ${ }^{2}$ Magnavita N, ${ }^{3}$ Sirpa Lusa, ${ }^{4}$ Judith Sluiter, ${ }^{1}$ Clas-Håkan Nygård

${ }^{1}$ University of Tampere, Tampere, Finland

${ }^{2}$ Università Cattolica del Sacro Cuore, Italy

${ }^{3}$ Finnish Institute of Occupational Health

${ }^{4}$ Academic Medical Centre, Coronel Institute of Occupational Health, Amsterdam, The Netherlands

\section{0a HOW TO PROMOTE HEALTH AND WORK ABILITY OF FIREFIGHTERS USING COMPUTER-BASED ASSESSMENT METHOD OF PHYSICAL WORK CAPACITY}

${ }^{1} \mathrm{~S}$ Lusa*, ${ }^{2} \mathrm{~A}$ Punakallio, ${ }^{2} \mathrm{~J}$ Halonen, ${ }^{2} \mathrm{M}$ Wikström. ${ }^{1}$ Finnish Institute of Occupational Health, Tampere, Finland; ${ }^{2}$ Finnish Institute of Occupational Health, Helsinki, Finland

\subsection{6/oemed-2018-ICOHabstracts.94}

Introduction According to the Finnish regulations the health and physical work capacity of operative firefighters has to meet the demands of work throughout their career, therefore they must be evaluated regularly. This study is part of large research and developmental project of the assessment, feedback and follow-up method of firefighters' physical work capacity (FireFit method).

Methods The aim was to find out short term effectiveness of the use of FireFit method. Web-based questionnaire was sent to 18 actors of all 22 regional rescue services (RRS) and to their occupational health personnel (OHP). The response rate was $60 \%$. In addition, the actors of two RRS and their OHP were interviewed about the developmental needs of the method especially concerning ageing firefighters.

Result The quality, equality and the use of tests in professional manner has improved. They reported that it has been easier to influence the problems of work ability using the system. As a whole, the comprehensive and work related feedback from the assessments has made discussion easier leading to the real causes of the problems and to wider health promotion issues. The consultation of OHP has been more prevalent and early enough, especially for persons with musculoskeletal problems. A total of $77 \%$ of the respondents felt that the quality and comprehensiveness of physical training has improved. However, there were also developmental needs. For example, in all RRS there should be an established and well-known action 